\title{
Defensive attack behavior in male and female rats
}

\author{
ROBERT J. BLANCHARD, CHARLES F. KLEINSCHMIDT, \\ CHANTIS FUKUNAGA-STINSON, and D. CAROLINE BLANCHARD \\ University of Hawaii, Honolulu, Hawaii 96822
}

\begin{abstract}
Male rats in a restraining tube bit and wounded the snout of an anesthetized male conspecific as a direct function of the intensity of tailshock, with bites declining systematically in the time interval after shock. Female rats' bites on a male rat were also dependent on shock, but did not produce wounds. When an anesthetized cat was presented to rats in the same situation, females bit and wounded the cat before shock was given, while the males again bit only in response to shock. These data were interpreted as indicating that male bites on both a conspecific and a predator fit the same defensive biting pattern. In contrast, females' bites on a male rat are actively inhibited, while females' bites on a predator are neither inhibited nor shock dependent: this latter finding may reflect the adaptive value (protection of the young) of attacking a predator before it hurts the female rat.
\end{abstract}

Recent attempts to describe and categorize defensive behaviors to threatening or painful stimuli have involved an increasingly more specific and complex pattern. When the threatening stimulus is a conspecific animal, the defensive behaviors of the rat include an elaborate set of "back-defense" reactions in addition to more general defensive behaviors such as flight and freezing (Blanchard \& Blanchard, 1977; Lehman \& Adams, 1977). Although both attacking and defending rats may bite conspecifics, the bites made by a defensive rat are distinguishable from the bites of an attacking animal on the basis of the site on the victim that is bitten; defensive rats bite almost exclusively at snout areas while attacking rats primarily bite the anterior and posterior back (Blanchard \& Blanchard, 1977).

One consequence of this distinction in bite target is that it may be applied to other situations in which bites occur, thus clarifying functional relationships within those tasks. Both "reflexive fighting" and "shock-elicited biting" (tailshock test) involve biting as a potential dependent variable; in both of these tasks, bites made on a conspecific occur almost exclusively in the area of the snout (Blanchard, Blanchard, \& Takahashi, 1978), like those made by defensive colony intruders. Thus, these situations appear to produce defensive biting rather than the aggressive reactions implied in the traditional view that they reflect "pain-elicited aggression."

The "shock-elicited biting" or "tailshock test" (Azrin, Rubin, \& Hutchinson, 1968) is especially informative in this context because bites to the snout

This research was supported by Grant MH-29163-01. Requests for reprints should be sent to Robert J. Blanchard, 2430 Campus Road, Honolulu, Hawaii 96822. of a conspecific are clearly dependent on shock, while bites to other body sites on a conspecific do not occur even when shock is given (Blanchard, Blanchard, \& Takahashi, 1978). Bites to a wood dowel, in contrast, frequently occur before any shock has been given: Azrin et al. (1968) were obliged to give hours of preshock habituation of the dowel-biting behavior to their subjects in order to reduce the level of this reaction. Tailshocks were given only after such habituation, and the dowel biting occasioned by these shocks might therefore be characterized as a "dishabituated" response rather than a reaction elicited by the shock. Therefore, bites to a dowel are not a clear example of either defensive or attack behavior.

In order to clarify the functional relationships of bites to animate and inanimate stimuli, and also to investigate possible sex differences in these relationships, the present studies describe bites by male and female rats to conspecifics or to a dowel as a function of shock intensity and the temporal proximity of pain. The second experiment extends this procedure to consider defensive attack behavior directed toward predators.

\section{EXPERIMENT 1}

\section{Method}

Subjects. The subjects were 12 male and 12 female albino rats from stock supplied by Simonsen Laboratories. These animals were 99 to 202 days of age and experimentally naive. They had been individually housed with ad-lib access to food and water from about 30 days of age. Males ranged from 342 to $437 \mathrm{~g}$ and females from 225 to $285 \mathrm{~g}$ in wieght.

Apparatus. The restraining tube for the male subjects was constructed from a 23.6-cm length of 5.8-cm-diam Plexiglas tubing, and the restraining tube for females was a $19-\mathrm{cm}$ length of $5-\mathrm{cm}$ Plexiglas tubing. Each tube contained a floor insert which provided a level space for the subject to lie on. These tubes were secured, lying horizontally, on separate $23 \times 15 \mathrm{~cm}$ wood plat- 
forms. A fixed wood dowel, $18 \mathrm{~cm}$ long and $.8 \mathrm{~mm}$ in diameter, extended beyond the rear opening of each tube, and a restraining bar could be fitted into the rear opening to prevent the animal from backing out. Outer surfaces of the tubes were painted black to restrict the subjects' field of vision to the target stimulus in the opening in the front of the tube. A BRS Foringer shock generator, Model SG-901, and a pair of electrodes were used to deliver shock to the subjects' tails. The target stimuli consisted of a $.8-\mathrm{cm}$-diam wood dowel and an anesthetized $(50 \mathrm{mg} / \mathrm{kg}$ sodium pentobarbitol) adult male rat, which was presented with its snout pointed toward the subject, just under the subject's snout.

Procedure. Each subject was held by the tail and allowed to crawl into the restraining tube. The backup bar was then put in place, and the subject's tail fastened to the tail rod with masking tape. The tail was then cleaned and electrode tape and electrodes applied. The subject was allowed $3 \mathrm{~min}$ to adapt to the restraining tube.

The test series consisted of five presentations of each target stimulus (wood dowel and snout of the anesthetized rat). Each such presentation was made by placing the target stimulus $1 \mathrm{~cm}$ below the snout of the subject for $4.2 \mathrm{sec}$. Within a series, $15 \mathrm{sec}$ elapsed between presentations, with a time lapse of $30 \mathrm{sec}$ between each series.

After an initial preshock series with each stimulus, a set of test series was run with increasing levels of shock. An ascending series was used because preliminary studies indicated that higher shock intensities produced enhanced responding during the next shock trials if these trials involved low levils of shock. Thus, counterbalanced shock series would have obscured the relationship between shock intensity and bite levels.

During these shock trials, the stimulus was presented for $2 \mathrm{sec}$ without shock, the shock was delivered to the subject's tail for $.2 \mathrm{sec}$, and the stimulus was left under the subject's nose for an additional $2 \mathrm{sec}$ after the termination of shock. The initial shock series was run with $2-\mathrm{mA}$ tailshock, which increased on succeeding series to $.4, .8,1.6$, and $5.0 \mathrm{~mA}$. After the shock series, there was a postshock series in which the stimuli alone were presented for an additional five trials. The order of the two target stimuli used was counterbalanced for the group of male subjects and the group of female subjects.

Finally, 1-2 min after the procedures described were completed, each subject was given a series of trials with .2-sec shock at 1.6-mA intensity. The stimuli were not present when the shock was given, but were presented for $2 \mathrm{sec}, 1,5,15$, or $28 \mathrm{sec}$ after the shock had terminated. The shocks were given every $60 \mathrm{sec}$, and the stimulus was presented once in the interval after each shock, with the shock-stimulus interval varied randomly until five trials at each shock-stimulus interval had been given.

During all trials, bites, wounds (bites with skin penetration), and gapes (1-cm opening of the subject's jaws) were counted before, during, and after shock. A high level of interrater reliability ( $97 \%$ agreement) for two trained raters was obtained in a pilot series. This good agreement was made possible because all shocks given were suprathreshold, and bites produced by shock occurred during movement and vocalization to the shock.

After each series, lesions on the target stimuli were counted. The anesthetized target rats were sacrificed by a further dose of anesthetic at the end of the session.

\section{Results}

Figure 1 presents the bite data for male and female subjects to the two target stimuli. As this figure indicates, little snout biting was observed before shock, while the proportions of bites during shock increased consistently as a function of the intensity of shock, to reach a very high level during shock and in the

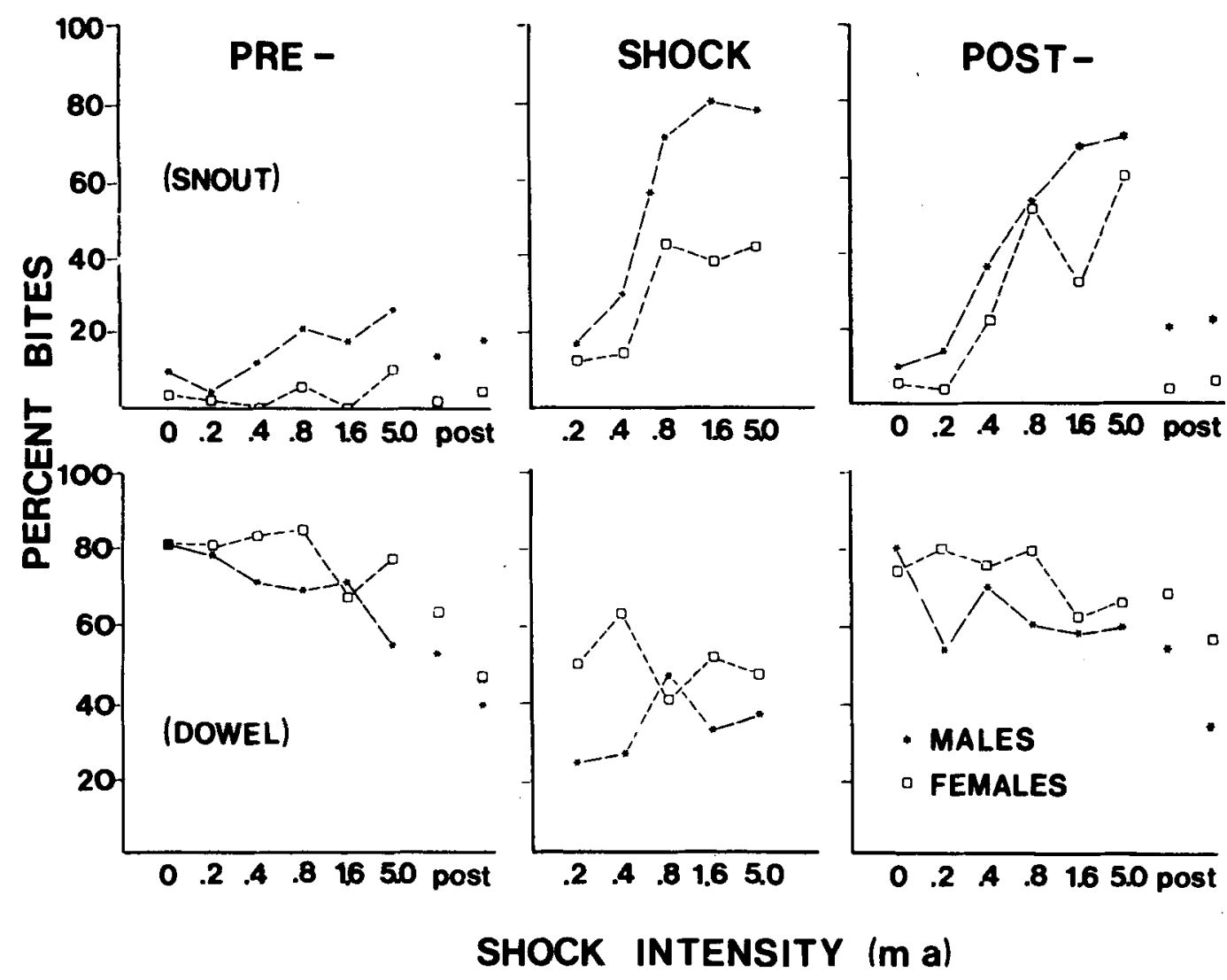

Figure 1. Percentage of hites by male and female rats to the snout of a male rat or to a wood Jowel before, during, and after shock on shock trials with shocks of differing intensities. 
2-sec postshock period for intermediate and high shock intensities. Although male and female rats showed similar trends during these periods, the proportion of bites made by males was consistently higher than that of females when the target stimulus was the snout of a male rat.

Dowel bites, however, produced a very different pattern: During the preshock periods of the shock test series, the frequency of biting was at a high level for both male and female rats, with the female bite level somewhat exceeding that of males. During shock, the frequency of dowel biting was much lower than that of snout biting, and there was no apparent relationship between shock intensity and the proportion of dowel bites. During the postshock periods, dowel biting was again higher than snout biting, and again there was no indication of an increase in these proportions when shock of a higher intensity had just been given. During both shock and postshock periods, female bites on the dowel were more frequent than male bites on the same stimulus.

These data were evaluated statistically by a 2 (sex) by 2 (target) by 3 (period: pre-, during, and postshock) by 5 (shock intensity) analysis of variance. The main effect of sex was not significant statistically $[F(1,22)=.15, p>.05]$, but the main effects of intensity $[F(4,88)=6.46, p<.001]$, period $[F(2,44)$ $=4.48, \mathrm{p}<.05]$, and target $[\mathrm{F}(1,22)=8.72, \mathrm{p}<.01]$ were. The Target by Intensity interaction was significant $[\mathrm{F}(4,88)=13.29, \mathrm{p}<.001]$, confirming that the association between snout bites and intensity was not paralleled for bites to the dowel. The Period by Intensity interaction was also reliable $[\mathrm{F}(8,76)=3.79$, $\mathrm{p}<.001$ ], as was the Target by Period interaction $[F(2,44)=61.96, p<.001]$. This last, highly significant, interaction is of interest in that it provides further evidence that the functions relating dowel biting to shock and snout biting to shock are different.

Although none of the two-way interactions with sex were significant, the Period by Intensity by Sex interaction was reliable $[\mathrm{F}(8,176)=2.05, \mathrm{p}<.05]$. This interaction and the Target by Intensity interaction appear to reflect a tendency for the higher shock intensities to produce more snout biting, especially for male rats, while no such increase for either male or female subjects was seen when the target stimulus was the dowel. This interpretation is confirmed by the results of subsequent analyses which indicated that, during shock, male rats made reliably more bites at the snout stimulus than did females [ $t(22)$ $=2.23, \mathrm{p}<.05]$; in this same period, the malefemale difference in dowel biting was not significant, although more female bites occurred.

Table 1 shows the incidence of gaping and of wounding (bites with penetration) by males and females during preshock and different shock intensities. When the snout of an anesthetized rat was used as the target stimulus, male rats gaped at this snout during $20 \%$ of preshock periods when the shock given was $.2 \mathrm{~mA}$ in intensity. This proportion rose consistently with higher shock intensities, to occur during about two-thirds of the preshock periods when higher levels of shock were given. Female rats, in contrast, showed a low frequency of gaping that did not change with increasing shock intensity. The overall difference in gapes for male and female rats was reliably statistically [between subjects, MannWhitney $U(12,12)=40, p<.05]$. When the dowel was used as the target stimulus, females did not gape at all and males showed $10 \%$ or fewer gapes at each intensity. The overall difference in gaping at the snout vs. the dowel was reliable for male rats (withinsubjects sign test, $p<.001$ ), while this difference was not reliable for female rats $(\mathrm{p}>.05)$.

Wounds on the conspecific snout during shock showed a pattern similar to that of gaping before shock; male rats made no wounding bites during .2-mA shocks, but their wound proportions rose steadily with higher shock intensities, to over $40 \%$ when 1.6- and 5.0-mA shocks were given. Females made no wounds at all until 1.6-mA shock, and even when $5.0-\mathrm{mA}$ shock was given they made less than $4 \%$ wounds. This overall male-female difference in wounding was reliable $[\mathrm{U}(12,12)=19.5, \mathrm{p}<.01]$. When the dowel was used as the target during shocks, males tended to make somewhat fewer penetrating bites than females [although the difference was not

Table 1

Gapes Before Shock and Percent Wounds During Shock for Male (M) and Female (F) Rats

\begin{tabular}{|c|c|c|c|c|c|c|c|c|c|c|}
\hline & \multicolumn{10}{|c|}{ Intensity } \\
\hline & \multicolumn{2}{|c|}{.2} & \multicolumn{2}{|c|}{.4} & \multicolumn{2}{|c|}{.8} & \multicolumn{2}{|c|}{1.6} & \multicolumn{2}{|c|}{5.0} \\
\hline & $\mathbf{M}$ & $\mathbf{F}$ & $\mathbf{M}$ & $\mathrm{F}$ & $\mathbf{M}$ & $\mathrm{F}$ & $\mathbf{M}$ & $\mathbf{F}$ & $\mathbf{M}$ & F \\
\hline & \multicolumn{10}{|c|}{ Preshock Gapes } \\
\hline $\begin{array}{l}\text { Snout } \\
\text { Dowel }\end{array}$ & $\begin{array}{r}20.00 \\
.00\end{array}$ & $\begin{array}{r}6.67 \\
.00\end{array}$ & $\begin{array}{r}36.67 \\
5.00\end{array}$ & $\begin{array}{r}13.33 \\
.00\end{array}$ & $\begin{array}{r}50.00 \\
8.33\end{array}$ & $\begin{array}{r}11.67 \\
.00\end{array}$ & $\begin{array}{l}68.33 \\
10.00\end{array}$ & $\begin{array}{r}10.00 \\
.00\end{array}$ & $\begin{array}{r}61.67 \\
8.33\end{array}$ & $\begin{array}{r}8.33 \\
.00\end{array}$ \\
\hline \multicolumn{11}{|c|}{ Shock Wounds } \\
\hline $\begin{array}{l}\text { Snout } \\
\text { Dowel }\end{array}$ & $\begin{array}{r}.00 \\
11.67\end{array}$ & $\begin{array}{r}.00 \\
36.67 \\
\end{array}$ & $\begin{array}{r}6.67 \\
13.33\end{array}$ & $\begin{array}{r}.00 \\
31.67 \\
\end{array}$ & $\begin{array}{l}23.33 \\
21.67 \\
\end{array}$ & $\begin{array}{r}.00 \\
18.33 \\
\end{array}$ & $\begin{array}{l}41.67 \\
16.67 \\
\end{array}$ & $\begin{array}{r}1.67 \\
26.67 \\
\end{array}$ & $\begin{array}{l}43.33 \\
10.00\end{array}$ & $\begin{array}{r}3.34 \\
26.67\end{array}$ \\
\hline
\end{tabular}




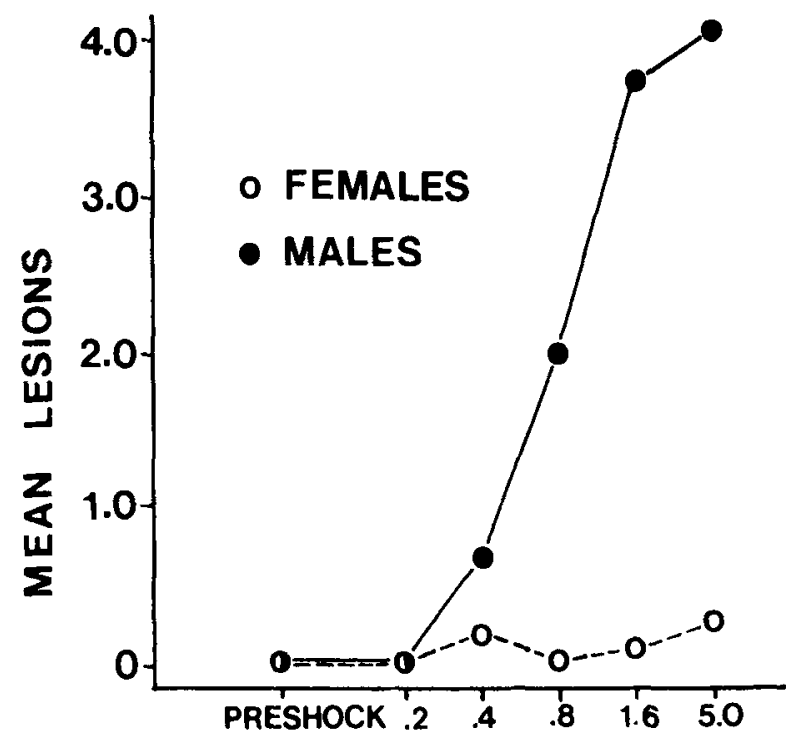

\section{SHOCK INTENSITY}

Figure 2. The mean number of lesions made by male and female rats to the snout of a male rat before shock and during shocks of different intensity.

significant statistically; $\mathrm{U}(12,12)=80, \mathrm{p}>.05$ ]. There appeared to be no consistent relationship between shock intensity and the incidence of "wounding" the dowel.

Additional data relating to male-female differences in bites to the snout of a conspecific may be seen in Figure 2, which presents lesion counts on the conspecific snouts used as targets after test series at each intensity. The relationship between the incidence of lesions and the intensity of shock given is obvious for male rat subjects and obviously nonexistent for female rat subjects. This overall malefemale difference was reliable $[\mathrm{U}(12,12)=24, \mathrm{p}<.01]$. Also, a sign test used to compare lesions made during .2-mA shock with lesions made during 5.0-mA shock, for male subjects, indicated a statistically reliable difference $(p<.01)$, although this same comparison was not reliable for female subjects $(p>.05)$.

Table 2 presents bite and wound data for male and female subjects as a function of time after shock. When the conspecific's snout was presented only $1 \mathrm{sec}$ after shock, male rats made bites on over $60 \%$ of presentations; by $5 \mathrm{sec}$ postshock and thereafter, the rate of biting had dropped sharply. This decrease from 1 to $28 \mathrm{sec}$ postshock was reliable by a sign test $(p<.01)$. For female rats, a similar drop in snout biting was seen, although this drop did not reach an acceptable level of statistical significance $(.10>p>.05)$. Also, the higher level of snout biting for males was statistically significant $[U(12,12)=37$, $\mathrm{p}<.05]$. Wound data were even more different for male and female subjects confronted with the snout stimulus: a single female made all the wounds for this group, and both of these wounds were made $1 \mathrm{sec}$ after shock.

Faced with the dowel, however, both male and female subjects bit and made "wounds" regardless of the time after shock. Although postshock interval differences in biting or wounding were not reliable for either male or female rats, females made significantly more bites on the dowel overall than did males $[\mathrm{t}(22)=2.44, \mathrm{p}<.05]$.

As each of these sets of data indicate, all of the dependent variables used [gaping, biting, biting with penetration (wounding), and direct measures of lesions on the target stimulus] tend to suggest a consistent set of relationships for sex, target, shock intensity, and temporal proximity. Each measure indicated or suggested that males show higher levels of "attack" on the snout of a male conspecific during shock than do females, and that the intensity of such "attack" increases during higher levels of shock. In contrast, gaping at a dowel is rare for both male and female subjects, but biting of the dowel is high for both. Moreover, such dowel biting is very common before and after shock and shows no relationship to the intensity of shock.

Other than indicating that bites on the dowel are not functionally similar to those made on the snout of a conspecific, these data do indicate what the functions of these bites may be. One possibility is that bites at the dowel reflect attempts to chew out of confinement; another is that dowel biting may be related to the tooth-chattering often shown by confined rats. In any event, it seems clear that dowel biting is as much a function of restraint as it is of shock, and essentially unrelated to either conspecific attack or defensive biting.

In contrast, the present snout-biting data strongly suggest that rats react to the snout of an anesthetized conspecific as if it were another rat; moreover, they react as if the other rat were attacking them. This has been seen previously in the clear preference of shocked rats to bite the snout of the target conspecific

Table 2

Percent Wounding and Biting

\begin{tabular}{|c|c|c|c|c|c|c|c|c|c|c|}
\hline & \multicolumn{8}{|c|}{ Time Postshock (in Seconds) } & & \\
\hline & \multicolumn{2}{|c|}{1} & \multicolumn{2}{|c|}{5} & \multicolumn{2}{|c|}{15} & \multicolumn{2}{|c|}{28} & \multicolumn{2}{|c|}{ Wounding } \\
\hline & $\mathbf{M}$ & $\mathrm{F}$ & $\mathbf{M}$ & $\mathrm{F}$ & $\mathbf{M}$ & $\mathrm{F}$ & $\mathbf{M}$ & $\mathrm{F}$ & $\mathbf{M}$ & $\mathbf{F}$ \\
\hline $\begin{array}{l}\text { Snout } \\
\text { Dowel }\end{array}$ & $\begin{array}{l}63.33 \\
50.00\end{array}$ & $\begin{array}{l}23.33 \\
65.00\end{array}$ & $\begin{array}{l}35.00 \\
50.00\end{array}$ & $\begin{array}{l}11.67 \\
66.67\end{array}$ & $\begin{array}{l}31.67 \\
43.33\end{array}$ & $\begin{array}{r}8.33 \\
78.33\end{array}$ & $\begin{array}{l}28.33 \\
41.67\end{array}$ & $\begin{array}{r}.00 \\
60.00\end{array}$ & $\begin{array}{l}68.42 \\
76.58\end{array}$ & $\begin{array}{r}8.00 \\
84.57\end{array}$ \\
\hline
\end{tabular}


in preference to other bodily loci offered, a preference identical to that of an intruder under attack by a dominant colony rat (Blanchard, Blanchard, \& Takahashi, 1978). From the present findings, it is also clear that these conspecific snout bites are temporally dependent on shock and are more frequent with higher shock intensities, strongly supporting the view that these are "retaliatory" or defensive bites.

The interpretation of snout bites during shock as "retaliatory" does, however, pose a further question. Why are female gapes, bites, and especially wounds and lesions so few? One possibility is that female bites at a conspecific male are inhibited even more than are the bites of a male rat at an attacking conspecific male. Such an interpretation is perhaps less parsimonious than the alternative view that female rats, being so much smaller than males, may simply be incapable of inflicting penetrating bites and lesions on the snout of a male rat. These possibilities were examined in Experiment 2.

\section{EXPERIMENT 2}

Experiment 2 provided an analysis of male and female rats' bites on an animate, but nonconspecific, target, a cat, as a function of shock intensity.

\section{Method \\ Subjects. The subjects were eight male and eight female rats, all naive adults derived from stock supplied by Simonsen Labora- tories. The males ranged in weight from 300 to $451 \mathrm{~g}$ and the females from 226 to $285 \mathrm{~g}$. \\ Apparatus. The apparatus consisted of the restraining tubes and shock apparatus used in Experiment 1. The target stimuli were a wood dowel, $.8 \mathrm{~cm}$ in diameter, and the snouts, forepaws, and tails of heavily anesthetized male cats. \\ Procedure. The subjects were placed in the restraining tubes, as in the first experiment, and the electrodes applied. The four target stimuli were presented $1 \mathrm{~cm}$ below the snout of the subject for five trials each, with no shock given, to establish a preshock trial baseline. Order of the series with the different targets was counterbalanced. Each stimulus presentation was $4.2 \mathrm{sec}$ in length. \\ The stimuli were then presented again, for an identical set of trials, with the exception that a .2-sec, 1.6-mA shock was given $2 \mathrm{sec}$ after the stimulus was presented. Thus, each subject had five trials with each stimulus without shock, and then, later, five trials with the same stimulus in which the .2-sec shock was given in the middle of the trial. Gapes, bites, wounds (bites with observed penetration) and lesions on the target were all scored as in Experiment 1.}

\section{Results}

During the no-shock, preshock, shock, and postshock trials with the dowel, male and female rats displayed a biting pattern very similar to that reported in Experiment 1: high and relatively consistent rates of biting at the dowel occurred before, during, and after shock on shock trials, with females slightly, but nonsignificantly $[\mathrm{U}(8,8)=27, \mathrm{p}>.05]$, higher than males in overall dowel bites. Females did make reliably more dowel bites than males before any shock had been given $[U(8,8)=9, p<.01]$.
For bites at the cat, a consistent pattern of sex differences in biting appeared: these are illustrated in Figure 3. When the cat's snout was presented during trials before any shock had been given, female rats bit the stimulus on $85 \%$ of these trials. No male rats made any bites at the cat's snout during this period. Before shock on those trials when shock was given, female rats continued to bite at a high rate, while male rats showed an intermediate level of biting. Male bite rates continued to rise during the shock and postshock periods, but failed to reach the consistently high bite rates shown by the females. Both the noshock bites and the bites during shock trials were reliably higher for females than for males $[\mathrm{U}(8,8)$ $=0, \mathrm{p}<.001$, and $\mathrm{U}(8,8)=8, \mathrm{p}<.01$, respectively].

When the cat's forepaw was presented, male bites were low both during the no-shock trials and during the shock trials. Female bites were high before any shock was given, and showed no overall change during the shock trials. As with the snout stimulus, the malefemale differences in biting to the cat's forepaw were reliable $[\mathrm{U}(8,8)=9, \mathrm{p}<.01]$. Both male and female rats showed reliably fewer bites at the cat's forepaw during shock than to the cat's snout during shock trials [sign tests, both ps $<.05$ ]. Neither female nor male rats showed any consistent tendency to bite at the tail of the cat.

In addition to biting the snout and forepaws of the cat, female rats also wounded these stimuli: During the no-shock period, nearly $56 \%$ of snout bites and $36 \%$ of paw bites were seen to penetrate, while $97 \%$ and $53 \%$ of bites to these same stimuli during the shock series produced wounds. This is comparable to the $87.5 \%$ wounds to the cat's snout made by male rats during shock periods (male bites during other periods were so few as to make comparisons of the proportions of wounds meaningless). As in Experiment 1, "wounds" on the dowel were consistently high for both male and female rats $(\mathrm{M}=25.69$ wounds for males and 27.36 for females), with an overall proportion (wounds to bites) of $94.87 \%$ for males and $79.59 \%$ for females.

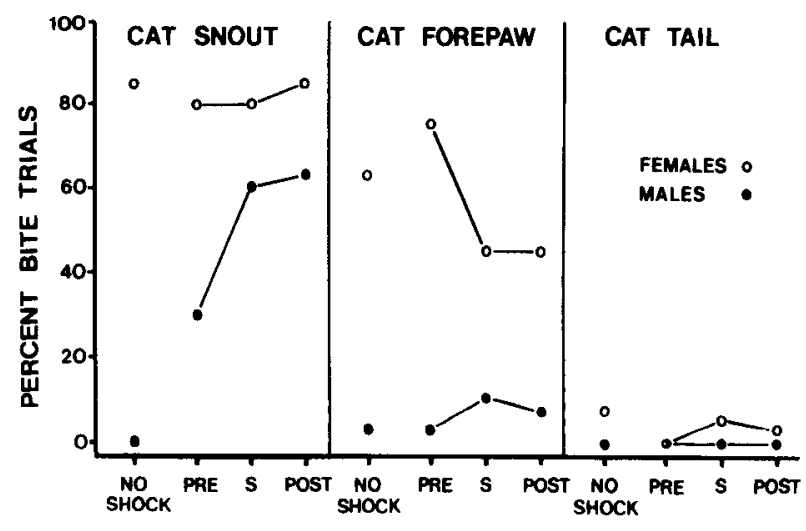

Figure 3. Percentage of trials on which male or female rats bit the snout, forepaw, or tail of a cat during no-shock trials and before, during, and after shock on shock trials. 
This pattern of sex differences in bites and wounds by female and male rats to an anesthetized predator is strikingly different from the sex differences in conspecific bites shown in Experiment 1. First, female rats were reliably higher, rather than reliably lower, in bites to the target stimulus. Second, the bites by female rats on the cat were independent of shock, while those few female bites on the conspecific targets were made during or just after shock. Finally, the proportion of female rat bites that resulted in penetration of the skin of the targets was consistently higher for the cat stimulus and consistently low for the conspecific stimulus.

There were some similarities between rat biting and cat biting. The cat's snout was clearly the preferred target for bites by male rats; female rats showed some preference for the cat's snout, although they were also inclined to bite its forepaws. Certainly, neither male nor female rats showed any inclination to bite at the cat's tail. Thus, there is a hierarchy of target sites on a predator as well as on a conspecific, although this is less marked than in the case of the conspecific target. This preference suggests that biting at a predator is functionally different from biting an inanimate dowel, as well as being somewhat different from conspecific bites. Only female rats showed such different rates and sites for biting a cat as opposed to a conspecific target; male rats' bites at the two classes of animate stimuli were similar.

These data suggest that there is a basic pattern of male bites and wounds on animate stimuli, after the biting animal has been hurt, which is not greatly different for conspecific and predatory stimuli: The male rat directs its attack to the snout, and bites only when it is being hurt. This is the "defensive attack" pattern seen in colony intruders as well as in the reflexive fighting situation. Female rats, however, show a more profound inhibition of attack tendencies when the stimulus is a male conspecific than do male rats, but less inhibition of biting and wounding when the animate stimulus is a potential predator.

The ability of female rats to wound the cat severely makes it clear that the relative lack of wounds on the male target stimuli in Experiment 1 is not due to a physical inability of these females to penetrate the skin of another animal. The cat-wound data therefore strongly suggest that the scarcity of female wounds on males is due to a specific, active inhibition of the strength of female bites toward males; perhaps this occurs because the larger males counterattack if a female does succeed in hurting them, and may possibly injure the female or her pups. Blanchard, Fukunaga-Stinson, and Blanchard (Note 1) have found that female rats bite frequently at a strange male intruding into their colony, but that these bites, like the present bites on males, do not wound. When female attack becomes intense, the intruder male does, in fact, retaliate.
Similarly, the lack of inhibition in female bites on a cat seems likely to reflect differing outcomes of attacks by male and female rats on predators: if a male rat is closely pressed by a predator, its best defense may be some combination of flight, back defense (since cats bite rats on the back of the neck), and freezing. Female rats may attain comparable personal safety by these maneuvers, but none of them afford any protection to the female's young; thus it appears plausible that female rats might increase their personal reproductive success by attacking such predators as cats, even before the cat has actually hurt them, if such attacks occasionally lead to the retreat of the threatening predator. The relationship between female bites on a cat and the tailshock task may, in fact, be even more specific: Since Rattus norwegicus usually nests in tunnels, a female might be expected to defend her litter by biting attackers at the tunnel entrance. Male-female differences in attack on predators may therefore be maximal when the rat is inside a tunnel, with the predator approaching the tunnel entrance. Certainly, both of these explanations for sex differences in defensive biting to conspecific and predatory stimuli require further investigation, and such investigation is presently underway in this laboratory. In summary, the present results contribute to an emerging conception of agonistic behavior in the rat, one which, in turn, may clarify a number of traditional views of the antecedents and functions of attack behaviors.

Blanchard and Blanchard (1977) have suggested that three different types of attack reactions may be distinguished in the rat. The first of these is conspecific or aggressive attack, involving a full range of behaviors from piloerection to actual biting, including lateral attack and on-top-of behaviors. These activities and the bites in which they culminate are totally different from the defensive attack behaviors seen in the present experiment.

Defensive attack is separable from aggressive attack on two grounds. First, it always occurs in response to pain or other intense threatening stimuli, in marked contrast to aggressive attack that is suppressed by such stimuli (Blanchard \& Blanchard, 1977). The present experiment demonstrates that defensive attack may be elicited both by predators and attacking conspecifics, although the character and frequency of such attack changes somewhat with the type of stimulus involved. Second, defensive attack is distinguishable from aggressive attack by the topography of the behavior itself. These attack reactions consist of a frontal jump or movement with a bite made at the snout of the threatening predator or conspecific. This movement is frequently accompanied by vocalization, and is seen in conjunction with other speciestypical defensive responses of rats, such as flight, freezing, boxing, and lying on the back. Both in terms of the topography of the attack and in terms of 
the other behaviors with which it is associated, defensive attack is totally dissimilar in form from aggressive attack in rats.

Aggressive and defensive attack toward animate objects both appear to be quite different from attack on a wood dowel. The first category of biting attack is inhibited by pain or fear, the second is strongly potentiated, while dowel biting is essentially unrelated to shock. The present study and that of Blanchard, Blanchard, and Takahashi (1978) indicate that high levels of dowel biting occur before shock, a phenomenon suggested by the Azrin et al. (1968) procedure of habituating dowel biting before giving shock. Dowel biting does occur when the rat is shocked, but its appearance cannot be viewed as dependent upon shock, unless long habituation (and other procedures such as substitution of a harder dowel) has been used to depress this behavior.

The third variety of attack described by Blanchard and Blanchard (1977), predatory attack, is under the control of even more different stimulus conditions, in that both hunger and the presence of prey are strongly related to the incidence of this behavior pattern. The topography of predatory attack also appears to be different from that of either conspecific or defensive attack (Paul \& Kupferschmidt, 1975).

In terms of the distinctions among these three types of attack behaviors, it may now be possible to reformulate and clarify two major theoretical statements with respect to aggression. First, descriptions of species-typical defensive behaviors to increasingly more severe or more imminent threat, have frequently included an aggression component (Bolles, 1971). The present study confirms the existence of such an attack pattern (Experiment 2), but further indicates that this biting attack on a predator is defensive attack rather than aggressive or predatory attack.

Finally, these findings clearly suggest modification of the classic hypothesis that "pain produces aggression." The present studies, as well as that of Blanchard, Blanchard, and Takahashi (1978), present consistent evidence that pain, associated with either the close presence of a conspecific or of a predator, will produce only one of the three varieties of attack behaviors, defensive attack.

\section{REFERENCE NOTE}

1. Blanchard, R. J., Fukunaga-Stinson, C., \& Blanchard, D. C. Female attack in albino rat colonies. Manuscript in preparation.

\section{REFERENCES}

Azrin, N. H., Rubin, H. B., \& Hutchinson, R. R. Biting attack by rats in response to aversive shock. Journat of the Experimental Analysis of Behavior, 1968, 11, 633-639

Blanchard, R. J., \& Blanchard, D. C. Aggressive behavior in the rat. Behavioral Biology, 1977, 21, 197-224.

Blanchard, R. J., Blanchard, D. C., \& Takahashi, L. K. Pain and aggression in the rat. Behavioral Biology, 1978, 23, 291-305.

Bolles, R. C. Species-specific defense reactions. In F. R. Brush (Ed.), A versive conditioning and learning. New York: Academic Press, 1971.

LEhman, M. N., \& ADAms, D. B. A statistical and motivational analysis of the social behaviors of the male laboratory rat. Behaviour, 1977, 61, 3-4.

PAul, L., \& Kupferschmidt, J. Killing of conspecific and mouse young by male rats. Journat of Comparative and Physiological Psychology, 1975, 88, 755-763.

(Received for publication October 11, 1977; revision accepted April 30, 1979.) 